\title{
Discurso ajeno y propio: función de las citas en las columnas periodísticas de Francisco Umbral
}

Jean-Pierre Castellani

\section{(2) OpenEdition}

Journals

Edición electrónica

URL: https://journals.openedition.org/cher/7552

DOI: $10.4000 /$ cher.7552

ISSN: 2803-5992

\section{Editor}

Presses universitaires de Strasbourg

\section{Edición impresa}

Fecha de publicación: 7 julio 2014

Paginación: 23-34

ISBN: 978-2-86820-569-8

ISSN: 1968-035X

\section{Referencia electrónica}

Jean-Pierre Castellani, «Discurso ajeno y propio: función de las citas en las columnas periodísticas de Francisco Umbral», reCHERches [En línea], 12 | 2014, Publicado el 13 diciembre 2021, consultado el 15 diciembre 2021. URL: http://journals.openedition.org/cher/7552 ; DOI: https://doi.org/10.4000/cher. 7552

Ce(tte) œuvre est mise à disposition selon les termes de la Licence Creative Commons Attribution Pas d'Utilisation Commerciale - Partage dans les Mêmes Conditions 4.0 International. 


\title{
Discurso ajeno y propio: función de las citas en las columnas periodísticas de Francisco Umbral
}

\author{
Jean-PierRe Castellani \\ Université François Rabelais - Tours
}

El columnismo, que es la forma más clara, confesada y reivindicada de la afirmación de un punto de vista personal en el discurso periodístico, ha conocido desde Larra y Clarín hasta Manuel Alcántara, Manuel Vicent, Rosa Montero, Elvira Lindo, Antonio Muñoz Molina, Javier Marías o Javier Cercas, un gran éxito que sigue vigente, a pesar de la evolución de los diarios hacia un discurso cada vez más frío y deshumanizado. De hecho, la columna siempre ha sido una prueba de periodismo informativo, de creación literaria y de libertad de pensamiento. Francisco Umbral ha sido, en España, sin duda alguna, incluso para sus detractores más agresivos, uno de los mejores, sino el mejor, representante de este columnismo, lo que reivindicaba con la conciencia de serlo:

Me leen diariamente un millón de personas, despliegan el periódico como un pájaro muerto y buscando mi firma, dan conmigo (Umbral 2001: 120).

La prensa española, quizás más que otras, ha reservado de modo tradicional un lugar eminente a este texto de tipo literario por su voluntad de dar opiniones junto a las informaciones. El diario $A B C$, por ejemplo, dedicó desde su creación, a principios del siglo $\mathrm{xx}$, una «tercera página» a la publicación de unos comentarios desconectados de la actualidad del día, escritos por un intelectual prestigioso, más bien académico, espacio que sigue hoy en día. 
El mismo Umbral veía la columna como «la silla isabelina del periódico, la antigüedad del Rastro para enseñar a los visitantes, el lujo literario de la empresa» (Umbral 2001:120) y lo reconocía cuando decía a Martínez Rico:

$\mathrm{Y}$ eso lo aprendí en los periodistas de $\mathrm{ABC}$ a los catorce años [...] Para ser un aristócrata dentro del periódico, no es más que el artículo, la columna de hoy (Martínez Rico 2001: 85).

En el discurso del diario de hoy, la columna de opinión, que no es exactamente el artículo, o la crónica informativa, o la reseña, o la necrológica, puede reunir todos esos tipos de periodismo en su propio texto. Le ofrece al lector, quien la busca y la goza, un texto marginado, en el doble sentido de la palabra, figurado y concreto, limitado a menudo por un recuadro que lo pone de relieve, destacándolo de los demás artículos: a la derecha o a la izquierda, en la última página o en un lugar estratégico, o sea un espacio que le permite al periodista/columnista/escritor practicar todas las libertades. Es sabido que Umbral exigió esa ubicación, en la contraportada del diario, lo que les daba un estatuto privilegiado a sus columnas.

De este modo, se suele establecer una relación desde un «yo» emisor predominante que firma, consciente de su poder de influencia, y un «yo» receptor cómplice. Entre ambos, se va creando una relación individual privilegiada, una especie de diálogo, una tertulia escrita con el lector que, en este caso, se vuelve un amigo fiel, un confidente. Éste va a buscar o recibir a este amigo como recibe la voz de un locutor de radio que le acompaña en su vida diaria.

Esa identificación no suele ocurrir con los otros artículos del periódico. A veces aparece la fotografía, la cara del autor, lo que humaniza más el texto y subraya la afirmación directa confirmando la autoría de la enunciación. Es significativo que haya sido Umbral el primer columnista en exigir una novedad gráfica con la aparición de una caricatura suya, por ejemplo en su primera columna diaria del Diario de León en 1961 (Caballé 2004: 143-167) y más tarde hará lo mismo con una fotografía suya al lado del título.

La presencia de la primera persona gramatical, que se justifica únicamente en los reportajes para dar autenticidad al testimonio, se torna aquí imprescindible, inherente al género. Sin esa autoría claramente reconocida, y por consiguiente injusta, equivocada, o subjetiva, no existe columna en su emisión ni en su recepción.

Hay una fuerza retórica persuasiva que domina en este ejercicio, con vistas a una toma de conciencia de algo por un lector orientado por la 
acumulación de argumentos y la riqueza del estilo adoptado. El predominio del «yo» del escritor/periodista explica que la columna se escriba desde sentimientos nunca neutros, sino más bien intensos: felicidad, plenitud, ira, ironía, irrisión, desilusión, compromiso. Como proclamaba Umbral: «Por esta razón me niego a firmar manifiestos. Ya firmo todos los días un manifiesto personal en mi columna» (Umbral 2000: 155) y en esta perspectiva su columna se vuelve un periódico en el periódico.

La crónica de Umbral, ha sido siempre una muestra atípica de un periodismo personal, arbitrario, subjetivo, individualista, anarquista, iconoclasta, entre la lírica y la sátira. Para él, el rumor «es una prenoticia» (Martínez Rico 2003: 110). «jamás he dado una noticia» (El Mundo, 26/02/1990) dice con orgullo. Lo que le importa es la literatura, o sea sus lecturas, su cultura, sus gustos.

Uno de los marcadores más significativos de este estilo recargado, seductor, reiterativo, es la abundancia de las citas literarias que hacen que encontremos, en los textos de Umbral, una especie de desdoblamiento casi permanente entre las propias reflexiones del articulista y una como ilustración de lo que afirma por medio de la cita de alguien, que puede ser o una persona de la actualidad política, o un gran escritor reconocido cuya autoría viene a reforzar el punto de vista del columnista.

La cita literaria, bastante usual en esos dos discursos de persuasión que son las columnas o las conferencias cultas, es pues una reivindicación en la enunciación ${ }^{1}$. Gracias a la autoridad de la persona citada, no se puede discutir ni poner en duda lo que afirma o proclama mientras que lo que dice el columnista puede ser dudoso. Se relaciona en este caso con el sentido jurídico de la palabra: citar delante de un tribunal a alguien es pedir su testimonio para reforzar el suyo. De este modo se establece una relación entre el texto y lo de fuera, lo que da más legitimidad al columnista que se beneficia del prestigio del autor citado.

Umbral siempre aprovechó el hecho de que la columna sea un género totalmente libre en su temática ya que puede abarcar todos los campos: políticos, culturales, económicos, deportivos, religiosos, nacionales o internacionales, locales o universales. En ella, el único límite fue, para él, el

1 George Steiner cuenta, en una entrevista periodística, a raíz de la publicación de su libro Grammaire de la création (Gallimard 2001) cómo en el momento de las manifestaciones del mayo de 68, le gritaron en una facultad de Frankfort en la cual había citado una frase, durante su conferencia: "Aquí ya no se cita», por ser la cita un acto de autoridad por excelencia. (Le Figaro littéraire, 12/04/2001, p. 3) 
espacio determinado de modo sistemático y regular (dos o tres folios). No le faltaron los temas, sobraban más bien, pero su meta siempre fue dar una visión personal, original, llamativa que hace que el lector termine lo que ha empezado. El placer de lectura provoca el deseo diario, casi urgente; su ausencia lleva al rechazo, a veces definitivo.

Lo aclara perfectamente el mismo Umbral afirmando: «Mucha gente me lee, pero nadie me asume. Yo diría que no me asumen, sino que sólo me consumen. Mi columna es un producto más de degustación» (Umbral 2000: 88). Es fascinante observar cómo Umbral ha venido escribiendo crónicas regulares, desde 1960 hasta su muerte en $2007^{2}$.

Observemos que Francisco Umbral es un seudónimo (se llama Francisco Pérez Martínez) o sea un apellido literario que adoptó cuando, joven periodista, llegó a León y se incorporó en 1958 a la emisora «La Voz de León», época en que empezó a publicar sus crónicas en el Diario de León.

Umbral nos presenta, en su columna «Los placeres y los días», en el diario El Mundo, una crónica de la sociedad española que consta no sólo de una galería de personajes famosos de la actualidad política, financiera, cultural sino también de una serie de observaciones críticas que constituyen un análisis terriblemente destructor, y por lo tanto, perturbador, sano, excitante, necesario, de la circunstancia histórica desde lo más nimio hasta lo más trascendental. La elección del título genérico de la columna refleja claramente su tendencia: acercamiento personal a un tema particular de la actualidad, comentario urgente de los acontecimientos políticos, grito vehemente de protesta.

Según las propias palabras de Umbral, la sección «Los placeres y los días» viene de Hesíodo que tituló así un libro. Tiene pues una fuente literaria

2 En 1976, fue el primer columnista de El País publicando secciones hasta 1988 con unos títulos muy literarios como: «El diario de un snob», «El spleen de Madrid», «Iba yo a comprar el pan». Durante tres años, desde 1984 hasta 1988, dejó de publicar un artículo diario, prefiriendo, a petición del director de El País, secciones semanales como «Mis queridos monstruos» (1984), «Las nuevas españolas» (1985), «Memorias de un hijo del siglo» (1986), «La elipse» (1986), «Los madriles» (1986-1988) que se acercaban más todavía al ensayo literario. A partir de junio de 1988 colaboró al Diario 16, durante doce meses, con una columna titulada «Diario con guantes» y con «Los iluminados» y, por fin, formó parte del equipo fundador de El Mundo, en 1989, periódico en el que publicó una columna diaria, desde entonces hasta 2007, bajo el título «Los placeres y los días», sin interrupción, salvo un corto, inesperado y fracasado paréntesis de 53 días en $A B C$, en 1993 con «Mitologías» o «Los iluminados», que son también títulos muy cercanos a textos literarios. 
como una gran parte de los títulos de novelas de Umbral ${ }^{3}$. Confiesa: «Creo que fue Hesíodo. Y de Marcel Proust. En principio el título de Hesíodo es Los trabajos y los días. Proust publica unos artículos suyos, aparecidos en la prensa de París, Los placeres y los días, lo cual es una ironía sobre el clásico porque él sustituye los trabajos por los placeres. Lo que quiere decir por otra parte, que al hecho de escribir no lo consideraba, pero en realidad trabajó muchísimo [...] Yo hago un periodismo, o columnismo, que tiene dos constantes, que son la política y la literatura. Esas dos constantes aparecen ya en este título: la vida mundana y el día tras día cada uno con su trabajo y su afán» (Martínez Rico 2003: 111)

Por falta de espacio vamos a centrar nuestra reflexión en las columnas sacadas de una serie de El Mundo, desde septiembre de 2005 hasta julio de 2006, o sea una temporada completa. Umbral, durante muchos años, sobre todo desde su instalación en la dacha de Majadahonda, en 1985, no vivió con el ritmo del año civil, del calendario objetivo sino con uno, más personal e íntimo acorde con su condición de periodista/escritor, cuya vida estaba dedicada durante la época que va de septiembre a julio a la escritura de una columna diaria en la prensa $y$, durante el verano, a textos de ficción ${ }^{4}$.

A lo largo de esos nueve meses descubrimos unas columnas cuya temática es tradicional en Umbral, como Septiembre $(01 / 09 / 05)^{5}$, El musical (07/09/05), La pobreza (16/09/05), La Gran Vía (28/09/05), La Guerra civil (29/09/05), Teoría del churro (31/09/05), Un camarero (11/10/05), El hambre (21/10/05), Las folklóricas (24/10/05), Madrid tiene un precio (29/10/05), Travesía del Manzanares (21/11/05), La oposición (01/12/05), Los papeles 21/01/06), Los oficinistas (01/02/06), Los sindicatos $(02 / 02 / 06)$, Los abuelos (01/03/06), Los padres (22/03/06), La crisis (10/04/06), La República (17/04/06), Los jornaleros 06/05/06), La vieja España (24/05/06), Las catalanas (20/06/06), Los biquinis (21/06/06), Ramoncín (01/07/06), Zidane (17/07/06), Los gamberros (18/07/06).

3 Recordemos las más significativas: se inspira en Pedro Salinas para Mortal y Rosa (1975), en Jean-Paul Sartre para Las respetuosas (1976), en Baudelaire para Mis paraísos artificiales (1976), en Marcel Proust para A la sombra de las muchachas rojas (1981), en Miguel Hernández para Un carnívoro cuchillo (1988), en Arturo Barea para La forja de un ladrón (1997), en Heidegger para Un ser de lejanías (2001).

4 Su muerte ocurrió el 28 de agosto de 2007, cuando preparaba sus futuras columnas por publicar en septiembre

5 A partir de ahora indicamos entre paréntesis las referencias a esas columnas con el orden siguiente: día, mes y año (desde septiembre 2005 hasta julio de 2006). Por ejemplo : 01/09/05. 
También podemos apuntar una tonalidad muy literaria en los mismos títulos de muchas columnas: Un clásico Mihura (10/09/05), Laberinto español (12/09/05), Platero y usted (21/09/05), Campmany y un señor de Murcia (01/10/05), Pinter (15/10/05), El Planeta (18/10/05), El ángel azul (09/11/05), La Enciclopedia (12/11/05), Dalí, hoy (15/11/05), Los tirantes de Montaigne (15/11/05), Leyenda del César visionario (19/11/05), Caballero Bonald (28/11/05), Unamuno, Maragall, Gallardón (02/12/05), El Motín de Esquilache (04/01/06), Duchamp (11/01/06), Baroja tampoco (19/01/06), Sartre en un bidón (20/01), Amado siglo XX (06/02), Don Pío (03/03/06), Andy Warhol (11/03/06), Luces de bohemia (08/04/06), Episodios nacionales (04/05/06), Larra en el Prado (09/05/06), Periodismo y compromiso (10/05/06), Los columnistas (17/05/06), El truco Da Vinci (19/05/06), López y Velázquez (26/05/06), Una tertulia de antaño (26/05/06), El maestro Baroja (27/05/06), El hombre que susurraba a los caudillos (14/06/06), Arte de lejanías (17/06/06), Dos dandis (24/06/06), Tartarín de Tarascón (26/06/06), Bodas de sangre (14/07/06), El humorismo (15/07/06), Poesía es comunicación (19/07/06).

Y como siempre en el columnismo de Umbral destacan unos aciertos lingüísticos en esos títulos: Un Papa a plazos (02/09/05), El neo machismo (23/09/05), Lampasados delluvia (14/10/05), Aznar, Rajoy, Pepiño (19/10/05), Felipe el silente (25/10//05), Talante, sonrisa y paciencia (07/11/05), Gramatiquerías (07/12/05), Amarillo es, amarillo es (10/12/05), Suevos, vándalos y alanos (16/01/06), Desespañolizar, (26/02/06), Vote botellón (17/03/06), Maduras y duraznos (23/03/06), Franco, gratis total (25/07/06).

Por otra parte, lo que llama la atención es que, para esos once meses, la lista de los autores citados es impresionante y testimonia la gran cultura hispánica y universal de Umbral que invade literalmente sus columnas: primero unos modelos literarios o estéticos desde Cervantes hasta Proust, o sea una cultura clásica, esencialmente poética, o ensayista, que evoluciona poco con el tiempo, y que se repite de modo obsesivo.

Luego aparecen muchos representantes del mundoliterariocontemporáneo como Delibes, Caballero Bonald, Barthes, Aleixandre, Saramago, Borges o Lipovetsky.

También, como ocurre siempre en Umbral, encontramos numerosas personalidades del arte como Velázquez, Goya, o Warhol, Modest Cuixart, Dorian Gray o del periodismo y del espectáculo como: Fernando FernánGómez, Luis G. Berlanga o Marilyn Monroe. Es cierto que a menudo se limita a sencillas enumeraciones de nombres pero su abundancia es significativa $y$ 
corresponde con lo que sabemos ahora de la Biblioteca de Umbral en su casa que constaba de miles de libros. Reflejan también sus amistades, su actividad social en Madrid con sus cenas, sus encuentros, los estrenos.

Por fin, en esta muestra, nos encontramos con una galería de personajes públicos, protagonistas de la actualidad, más bien política, durante esos once meses, como Felipe González, José María Aznar, Esperanza Aguirre o Mariano Rajoy.

Podemos observar que en 2005-2006 es casi el mismo índice onomástico que ya nos presentaron memorias y semblanzas anteriores como Mis queridos monstruos (1985), Crónica de esa guapa gente (1991), La década roja (1993), Las palabras de la tribu (1994), Los cuerpos gloriosos (1996) o La derechona (1997), lo que ilustra la permanencia de las referencias culturales de Umbral y quizás su carácter clásico, sobre todo en el mundo del arte y de las letras, menos por supuesto en el mundo político, más dependiente del contorno urgente e inmediato. Son memorias a la vez de la jet y semblanzas literarias.

Todos aparecen marcados tipográficamente por las famosas negritas, que son la tipografía acostumbrada para referirse a los apellidos de los conocidos en las columnas frívolas de cotilleo de las páginas de sociedad. Pero aquí, no se trata de un código de prioridad o superioridad social sino, más bien, de una marca formal que destaca de este modo a la gente a la que se refiere en la columna. Es cierto que hay aquí un peligro de contaminación que a menudo ha perjudicado el mensaje de Umbral, asimilado a algo que no es en absoluto, o sea el comentario superficial de unos acontecimientos vividos por una minoría aristocrática, financiera o artística.

La columna se inspira pues en unos acontecimientos ajenos al autor pero al mismo tiempo refleja una selección coherente desde hace décadas. Esos hechos no forman parte de su propio destino y sin embargo escribir de ellos constituye su vida.

Así, aparece de modo sistemático, otro discurso, un texto ajeno, mucho más importante, con esas citas de grandes autores o críticos. La autoría personal de Umbral se manifiesta, por consiguiente, por medio de un sistema bastante complejo de introducción de un texto ajeno en el suyo. Son unos signos que destruyen la neutralidad del discurso, lo mismo que un fundido encadenado o un travelling destruyen la neutralidad del discurso fílmico, llamando directamente la atención del lector y subrayando unos elementos lingüísticos del texto. 
Umbral suele hacer esas citas de memoria, sin referencia precisa, ni siquiera cita textual, pocas veces entre comillas: en general se trata de un gran maestro de las letras universales como Heidegger, Cernuda o Nietzche. Abundan los ejemplos típicos con esas fórmulas repetidas: lo dijo el poeta (01/09/05), escribió Ortega (07/09/05), a lo que llamaba Lorca, como decía Tierno Galván, el propio Hernández lo dejó escrito (21/09/05), que dijo Rilke, como cantó Jorge Guillén (30/09/05), decía B. Russel (21/10/05) como diría Lipovetsky (07/11/05) como escribiera don Luis de Góngora y Argote (05/12/05), que Rafael Alberti llamó capital de la alegría plagiando a Eluard (05/12/05), dejó escrito nuestro Ortega y Gasset (05/01/06), Lo escribió Juan Ramón Jiménez (09/01/06), que decía Quevedo (19/01/06), como decía Pérez Ferrero (30/01/06), así lo vio y lo cantó Miguel de Unamuno, escribió Simenon que toda familia esconde un cadáver en el armario (01/03), una transvaloración de todos los valores como escribiera Nietzsche (14/03/06), lo decía Andy Warhol (25/03/06), como decía el maestro Lázaro Carreter (05/04/06), y dijo Baudelaire (17/07/06), lo escribió para siempre Vicente Aleixandre, como dice Marsé (18/10/06).

Umbral alterna las referencias precisas y las anónimas: a menudo, como si no tuviera ganas o tiempo de buscar la fuente exacta se contenta con unas expresiones vagas como: alguien dijo (03/09/05), lo escribió un catalán de universalidades (05/09/05), lo escribió Eugenio d'Ors (05/09/05), dijo Carlos $V$ o se le atribuye, escribió Ortega... (07/09/05), Así perdió los brazos la Venus de Milo, que decía don Eugenio d'Ors que tenía brazos de haber tenido muy buenas manos (15/09/05), decía Cela (25/11/05), Dejó escrito nuestro Ortega y Gasset que toda la música, desde Beethoven a Wagner, no es sino melodrama... (05/01/06), como dijera el filósofo (02/03/06), como hubiera dicho Machado (03/03/06), que decía Quevedo (15/03/06), como lo hubiera escrito Apollinaire (17/04/06), dice Raúl del Pozo... (20/04/06), decía Sartre que la única manera de pensar y seguir es impugnar (26/05/06), cuenta Pablo Neruda que él, cuando cónsul en la India, comprobó que los cónsules se aburren mucho en todas partes... (12/06/06), como hubiera dicho Quevedo (14/07/06), como la vivió y palpitó el poeta (24/05/06), cuenta alguien muy cercano a él (15/06/06), y ya dijo Baudelaire que hay que embriagarse de vida, de muerte, de amor, de mujer, de sangre (01/07/06), ya dijo Baudelaire que para crear hay que embriagarse de sangre. Y para meter goles también (17/07/06), lo dijo el poeta: «Todas las rosas son la misma rosa» (01/10/06).

Esas fórmulas suelen introducir una reproducción más o menos exacta o literal de las palabra escritas o pronunciadas por esas personas: nuestra 
común amiga, Carmen Rigalt, escribió aquí el otro día (09/09/05), me contaba César González Ruano (16/11/05), A José Antonio Marichal, un día me lo encontré en El Escorial y me dijo... (12/01/06), me dijo Laín Entralgo (07/01/06), Carmen Díez de Rivera me decía (27/04/06), le oí decir a Mayor Oreja (04/07/06), como me dijo una vez Antonio Machín (18/07/06).

Otras veces la cita se reproduce textualmente, según las normas acostumbradas: fuente nominal, uso de los dos puntos y de los guiones para encerrar claramente la cita en su propia lógica. "Yo soy otro» dijo Rimbaud (01/09/05), El propio Hernández lo dejó escrito: «Un carnívoro cuchillo de ala dulce y homicida sostiene un vuelo y un brillo alrededor de mi vida» (21/09/05), o sea «rosa, pura contradicción, entre tantos párpados», que dijo Rilke (26/09/05), "Lo tan real, hoy lunes» como cantó Jorge Guillén (30/09/05), Hasta que llega Agustín de Foxá va y dice: "Los rascacielos son el gótico de nuestro tiempo" (31/09/05), Lo escribió Juan Ramón Jiménez: «La primavera, niña errática y desnuda, va a ofrecerle a la vida un nuevo traje y busca inspiración en el paisaje» (01/10/05), como cantara Antonio Machado: «Mi infancia son recuerdos de un pato de Sevilla» (14/10/05), su prosa valiente, ágil, expresiva "y bella de sangre contraria» como las navajas de Lorca (04/11/05), luego como dijera Eugenio d'Ors de manera inmortal «los experimentos, joven, se hacen con gaseosa» (30/11/05), «de la música nace toda cosa» había escrito el viejo Verlaine (10/12/05), El presidente de Cantabria, Miguel Angel Revilla le ha dicho a Zapatero al tiempo de jurar la bandera española: «Me pone España» (30/12/05), Decía Jean-Paul Sartre que «el tiempo no existe; sólo existe el paso del tiempo» (07/01/06), El catalanísimo Eugenio d'Ors canta así a Rosalía de Castro: «Sobre la ría un astro se moría; Rosalía de Castro de Murguía» (16/01/06), les duele España como a Primo de Rivera, aquel me dijo: «Amamos a España porque nos gusta» (26/02/06), me lo decía Alejo Carpentier en su embajada de París todas las mañanas: «No es aconsejable hacer una revolución literaria que luego se queda en manos de los escritores, como es el caso del Ché» (27/02/06), sin volver a ver «la estrella numerosa» que dijera Eugenio Montes (13/03/06), lo decía Andy Warhol: «Siempre he pensado que la mejor manera de medir las cosas es el tamaño» (25/03/06), Camilo Cela era más bien de los judíos: "Los árabes no nos han dado nada» (04/04/06), «no me propongo contarle al público mi vida personal entera» Manuel Azaña (17/04/06), en esta «caza de iberismos» que diría Ortega (24/05/06), como decía Tierno Galván: «Dios no abandona a los buenos marxistas» (14/06/06), recordemos aquel verbo audaz de Álvaro de Laiglesia: "Cómo fragan las señoras» (21/06/06), «Poesía es comunicación» 
lo escribió para siempre Vicente Aleixandre (19/07/06), Ramón Gómez de la Serna decía que: «Madrid es moro» (22/07/06), escribió Verlaine que «de la música nace toda cosa» (30/06/06).

Así que la frase del otro no solamente es un adorno, un guiño cultural, una exhibición de erudición, sino que es además un reforzamiento de su propio discurso. El periodismo cita a testigos o a actores de los acontecimientos pero no suele acudir a ese tipo de citas. El recurso a la frase significativa de autores famosos le quita valor informativo a la columna y la asemeja más bien a la retórica literaria. No se sitúa pues en un plano de verdad objetiva sino en un plano mucho más general de verdad absoluta.

De este modo se sitúa evidentemente en la escuela tan española del periodismo literario, en «la vieja artesanía de hacer artículos para la prensa, entre la política y la poética» (Umbral 1993: 210) más cerca de la poesía que de la política, por ser Umbral ante todo, poeta. Esta crónica de sociedad, que podría resultar algo rápidamente superado por la actualidad devoradora, viene a ser una obra de arte, una auténtica creación literaria por nutrirse de la misma literatura, entre documento sociológico y creación estética.

Podemos deducir pues de toda esa actividad regular y voluntaria que, desde siempre, Umbral ha compaginado una colaboración con órganos de prensa no como periodista sino como escritor de periódico o en periódico y una creación propiamente literaria como si el novelista necesitara ese contacto permanente con la observación de la realidad contemporánea y ese diálogo regular con sus lectores.

La lista de los títulos de las columnas puede dar la impresión de un conjunto caótico solamente si se mira desde fuera: esta crónica de sociedad que podría resultar algo frívolo con sus negritas o algo rápidamente superado por la actualidad devoradora, viene a ser una obra de arte, una auténtica creación literaria, entre el reportaje y la novela, entre realidad y ficción, entre documento sociológico y creación estética. No hay fronteras entre los textos de Umbral que ocupan espacios muy vecinos como la columna, el diario íntimo, la novela lírica y la autobiografía. Son modalidades de la misma materia, unificadas por el lenguaje siempre muy cuidado y renovado por un trabajo permanente del idioma. Así que hay un trasvase permanente entre la vida del autor y su obra, partiendo de una creación simultánea: Umbral habla de literatura en sus columnas, y de sus columnas en sus textos de confesión o de ficción. En definitiva, la única obsesión verdadera es la misma literatura a través de un ejercicio obsesionado por un cuerpo a cuerpo con el idioma. Lo que cuenta, para Umbral, es escribir: «Escribir es ejercitarse para 
no morir» (Umbral 1999: 52) y escribir este artículo vino a ser para Umbral como «un placer gimnástico de la mente» (Umbral 1999: 174).

Al fin y al cabo esa crónica de sociedad se vuelve una anti-crónica de sociedad, con una tremenda carga de testimonio y de denuncia.

La consulta de las columnas de Umbral da un panorama algo completo de la problemática del año en todos los campos (quizá un gran ausente sea el deporte). Pero todo parte de la mirada, de la cultura, de la sensibilidad y sobre todo de la memoria del propio Umbral. Hablando de lo que pasa en España habla de sí mismo y hablando de sí mismo nos permite descubrirnos.

Por eso, pensamos que era absurdo exigirle a Umbral, como lo han hecho a menudo unos críticos, que dejara de dedicar tanto tiempo a la columna diaria y que escribiera por fin, según ellos, una gran novela tradicional. No tomaron en cuenta que Umbral había encontrado, en la práctica de la escritura diaria de una columna, y en la construcción de sus textos narrativos a partir de la estructura de columnas acumuladas, un espacio que le permitía gozar de todas las libertades y juntar memoria personal y memoria colectiva, el subjetivismo más radical y la observación más entregada a conocer y aclarar el mundo que nos rodea. Apunta aquí la conciencia de una situación y de un papel singulares en el discurso del diario. En esta perspectiva se confirma que para Umbral «el artículo es la heterodoxia dentro de la ortodoxia del periódico» (El Mundo, «Benítez Reyes columnista», 12/12/2000).

En definitiva, el aparentemente narcisista Umbral manifiesta en la columna una voluntad obsesiva de testimoniar, de purificar y de escribir que pasa, entre otros motivos, por la cita de otros escritores, lejos de cualquier exhibicionismo, pose frívola o autocomplacencia pedante. Pensamos que no se entiende bien el alcance de la obra de Umbral si no se considera que, para él, existencia y escritura se confunden hasta tal extremo que el forcejeo con las palabras, o sea el trabajo estilístico, resultan una verdadera terapia obligada para superar una tendencia cada vez más pronunciada hacia una autodestrucción y una violencia desgarradora.

Representaba, para él, un modo de careo permanente con la actualidad política, interior sobre todo, social y cultural. Por medio de una invención verbal, era como un desafío que se lanzaba a sí mismo cada mañana, una droga necesaria a su supervivencia. Como confiesa el mismo Umbral: «Soy un escritor doloroso que se cura escribiendo» (Umbral 1999: 161). Sabemos que Umbral no tenía textos preparados, congelados, susceptibles de salir en caso de urgencia, lo que prueba el nexo estrecho y visceral de la escritura con su vida. 
Además de una función ornamental la cita participa de la amplificación retórica del razonamiento. Presentarla como un recuerdo personal (una lectura o algo de su propia biblioteca) es una posibilidad para el redactor de la columna, como Umbral, de irrumpir en su propio texto, no de un modo vanidoso (prueba posible de su cultura y de su erudición) sino de manera individualizada.

Podemos decir por lo tanto que una cita no es una digresión que aleja de su texto, o una redundancia que lo duplica, sino más bien algo que se adentra en nuestro discurso. Como dice Antoine Compagnon: «La citation ne va pas du texte vers son dehors, elle appelle, convoque, fait venir ce dehors et elle l'incorpore» (Compagnon 1979: 291).

Es evidente que la visión de la España de los cincuenta últimos años, con la guerra civil, el poder de Franco, el tardofranquismo y la democracia, pasan por la criba de la mirada de Umbral, parecida a la muy aguda de un Quevedo o de un Voltaire. Y con esto el columnismo deja de ser un género segundario, o marginado para formar parte de un conjunto creativo que se elabora paralelamente pero que resulta enriquecido por esa reflexión diaria muy personal que se enriquece sin embargo con la de los demás.

\section{Bibliografía}

Caballé A., 2004, Francisco Umbral, el frío de una vida, Madrid, Espasa Hoy.

Compagnon A., 1979, La seconde main, París, Seuil. Martínez Rico E., 2001, Umbral: vida, obras y pecados, Gijón: Libros del Pexe.

Martínez Rico E., 2003, Las verdades de un mentiroso ilustre, Gijón: Libros del Pexe. Umbral F., 1993, La década roja, Barcelona, Planeta.

Umbral F., 1994, Mis placeres y mis días, Madrid, Espasa-Calpe.

Umbral F., 1999, Diario político y sentimental, Madrid, Planeta.

Umbral F., 2000 Madrid, tribu urbana, Madrid, Planeta.

Umbral F., 2001,Un ser de lejanías, Madrid, Planeta. 